\title{
Mito e imaginário social: uma proposta de análise acerca da atuação da DOPS em relação ao PCB no norte do paraná (1945-1953)
}

\section{Myth and social imaginary: an analysis proposal on the performance of DOPS with regard to PCB in northern paraná (1945-1953)}

\author{
Verônica Karina Ipólito*
}

\begin{abstract}
Resumo
O objetivo central deste trabalho é analisar as representações da Delegacia de Ordem Política e Social (DOPS) frente à atuação dos militantes do Partido Comunista do Brasil (PCB) na região norte do Paraná no período compreendido entre o fim do regime estadonovista e a promulgação da Lei de Segurança Nacional (LSN), em 1953. Sendo a DOPS um órgão de controle social, serão levados em conta os mecanismos de repressão acionados pelo Estado, cujo objetivo era manter a ordem estabelecida. O período entre 1945 e 1953, no estado do Paraná, foi marcado pela efervescente organização dos trabalhadores rurais, sobretudo sintetizada na luta pela terra, como foram os casos da Guerra de Porecatu e da Revolta do Sudoeste, e por uma luta política cotidiana nas cidades, sejam pelos debates políticos do final da Segunda Guerra e do processo de legalização do $\mathrm{PCB}$ e sua posterior proscrição ou dos constantes movimentos sociais urbanos. A atuação da polícia política neste período se configura ainda pelo controle político-cultural ou de qualquer forma de expressão que signifique ameaça à ordem social estabelecida. A abordagem da pesquisa dará destaque à cultura política ressaltando seu papel nas relações de poder, levando em conta as representações, valores, tradições e cultura dos atores sociais envolvidos nos movimentos. É intenção do trabalho, portanto, demonstrar que o período aqui discutido se tratou de um período contraditório, onde em teoria havia liberdade, mas na prática o poder do Estado inibia direitos de decidir e agir.
\end{abstract}

Palavras-chave: DOPS-PR. PCB. Cultura política.

\begin{abstract}
The purpose of this work is to analyze the representations of the Bureau of Political and Social Order (DOPS) compared to the actions of militants of the Communist Party of Brazil (PCB) in the northern region of Paraná in the period between the end of the New State regime and the promulgation of the
\end{abstract}

\footnotetext{
* Doutoranda em História pela Universidade Estadual Paulista Júlio de Mesquita Filho (UNESP-Assis, SP). E-mail: veronicaipolito@yahoo.com.br
} 
National Security Act (LSN) in 1953. Being DOPS an organ of social control that takes into account the mechanisms of repression triggered by the state, whose goal was to maintain the established order. In the period from 1945 to 1953 the state of Paraná was branded by the effervescent organization of the rural workers, mainly synthesized by the struggle for land, as it was the case of the War of Porecatu, the Uprising of the Southwest and by a daily political struggle in the cities, be it by political debates by the end of the Second War, the process of legalization of the Brazilian Communist Party and its subsequent proscription or in constant urban social movements. The role of political police in this period is still set for political control, cultural or any form of expression that means a threat to established social order. The research's approach will highlight the political culture emphasizing its role in power relations, taking into account the representations, values, traditions and culture of the social actors involved in the movements. It is the intention of the work, therefore, to demonstrate that the period discussed here was a contradictory period where there was freedom in theory but in practice the power of the State inhibited the rights to decide and act.

Keywords: DOPS-PR. PCB. Political culture.

\section{INTRODUÇÃO}

O tema que permeia a problemática desse artigo se refere à trajetória política do Partido Comunista do Brasil (PCB) na região norte do Paraná, no período entre 1945 e 1953, e a ação da Delegacia de Ordem Política e Social (DOPS) frente à atuação desses militantes. O tema aqui proposto está situado, portanto, no campo de "estudo das mentalidades políticas e das representações". ${ }^{2}$ Trata-se de compreender e reconstruir a política e suas ações e representações, o choque de identidades, das lutas e adaptações, os conflitos e as alianças que fizeram a experiência comunista no norte paranaense.

O PCB, desde sua criação em 1922, sempre procurou ser reconhecido e atuar livremente na política brasileira. No período que compreendeu seu nascimento até sua legalização definitiva em 1985, o partido teve menos de três anos e meio de legalidade plena. Nesse sentido, consideramos ser fundamental analisar, por intermédio de documentos da polícia política, algumas estratégias utilizadas pelo Estado para continuar com o aparato repressivo da Era Vargas, legitimando não apenas um novo regime, conhecido equi-

2 CAPELATO, M. H. R.. Historia Política: historiografia. Revista de Estudos Históricos, Rio de Janeiro, v. 9, n. 17, p. 4, 1996. 
vocadamente como "interregno democrático", mas que contribuiu para o prolongamento da "lógica da suspeição". ${ }^{3}$ Nessa perspectiva, todo indivíduo que atentasse contra o controle da sociedade continuaria sendo um inimigo em potencial. A partir dessa constatação empírica, objetiva-se analisar as representações da polícia política em relação ao PCB no norte do Paraná como parte da estratégia utilizada pelo Estado para perseguir os suspeitos considerados perturbadores da ordem pública. Instrumento precioso da "lógica da suspeição" e, portanto, da legitimação do novo regime que se convencionou chamar de democrático. A construção de mitos políticos foi mecanismo de significativo investimento estatal, particularmente do mito da conspiração comunista internacional, que se cristalizou no imaginário social. As regras instituídas pelo poder policial são reveladoras não apenas do aparato de exclusão engendrado pelo Estado como também são expressivas de símbolos acionados com o objetivo de legitimar, no que concerne ao imaginário coletivo, a ideia de "grupos perigosos" ou de "inimigos-objetivos". ${ }^{4}$ No dizer de Emiliana Andreo da Silva: ${ }^{5}$

Geograficamente, todos os espaços eram vigiados pelo "olhar" treinado das autoridades policiais que, ao longo do século XX, transformaram as fichas de identificação e os relatórios de investigação em registros de controle social. Todo cidadão - de qualquer sexo, religião, raça e nacionalidade - era um suspeito em potencial. E o perigo de uma sublevação contra a ordem instituída não tinha endereço certo: tanto poderia vir do campo como da cidade, ser liderada por um homem simples, sem cultura, ou por um intelectual renomado.

Nessa perspectiva, o investimento do Estado em campanhas anticomunistas é indispensável para a consolidação de um projeto político sem questionamentos, mesmo após o fim do regime getulista em 1945. Por isso, uma das hipóteses da investigação é a de que a Constituição de 1946 não estava sendo cumprida na íntegra. Considerada por muitos como símbolo da democracia, consagrando as liberdades previstas na Constituição de 1934, a Carta Magna de 1946 marcou a recuperação da liberdade e a restituição dos órgãos democráticos. No entanto, no dia 7 de maio de 1947, por decisão do Tribunal Superior Eleitoral, o PCB é colocado na ilegalidade, contradizendo o que dizia a Constituição de 1946.

3 "Lógica da suspeição": todos os indivíduos estavam "sujeitos" à subversão, e era papel da DOPS investigar e fichar os "suspeitos" de praticar a perturbação da ordem pública.

4 ARENDT, H. As origens do totalitarismo. São Paulo: Companhia das Letras, 1991.

5 SILVA, E. A. da. O despertar do campo: lutas camponesas no interior do Estado de São Paulo. São Paulo: Arquivo do Estado - Imprensa Oficial do Estado, 2003. p. 18. 
A intimidação dos militantes comunistas não foi um caso exclusivo no Brasil. Eric Hobsbawm ${ }^{6}$ considera que o fim da Segunda Guerra Mundial provocou o "relaxamento" do anticomunismo. A consciência de luta comum manifestada nesse intervalo de dois anos foi aniquilada com o rompimento da aliança entre os Estados Unidos e a União Soviética no pós-guerra. Em 1947, os ministros comunistas dos governos ocidentais foram varridos de seus cargos. Houve a mesma reação em países governados pelo comunis$\mathrm{mo}^{7}$. O período marcado pelo "relaxamento" do anticomunismo saiu de cena para estrelar "os anos perigosos de 1947 até os dramáticos fatos da Guerra da Coreia".

No Brasil esses sintomas puderam ser sentidos com a cassação do PCB em 1947 e a promulgação da Lei de Segurança Nacional (LSN) de 1953ㄹ, que definia crimes contra a segurança externa ou interna do Estado e também contra a ordem política e social. Se a restrição aos comunistas se tratava de um fenômeno mundial e a política brasileira vivia um período democrático, por que houve, então, a necessidade de cassar o registro do PCB e sancionar mais uma lei de segurança nacional? Não seriam essas atitudes mecanismos de repreensão que vão contra a liberdade proposta pelo Estado? Desse modo, trabalharemos com a perspectiva de que a repressão, em termos, continuou, chegando a adotar formas superiores de violência, exemplificadas na intensificação de ações coercitivas aos movimentos sociais e em particular às organizações políticas de esquerda. Por isso, uma de nossas pretensões é trabalhar o fato de que esse momento não era tão democrático quanto se pensava. Assim, pensar a República no Brasil no período aqui proposto (19451953) requer ponderar as práticas voltadas ao interesse público na medida em que as autoridades - influenciadas ou não por organismos externos ou internos - visam transmitir a imagem na qual, enquanto governantes, esta-

6 HOBSBAWM, E. Tempos interessantes: uma vida no século XX. São Paulo: Cia. das Letras, 2002. p. 198.

7 Ibidem. p. 204.

8 HOBSBAWM, E. Era dos extremos: o breve século XX (1914-1991). São Paulo: Cia. das Letras, 1995. p. 239.

9 No momento do pós-guerra, o controle da sociedade civil encontrava fundamento nas respectivas Leis de Segurança Nacional dos anos 1935 e 1938. Promulgada em 4 de abril de 1935, a LSN definia crimes contra a ordem política e social. Sua finalidade era transferir para uma legislação especial os crimes contra a segurança do Estado, sem as garantias processuais. Foi seguida da Lei de Segurança Nacional de 1938, decreto-lei 431 de 18 de maio de 1938, na qual foram minimizadas ainda mais as condições de defesa dos acusados: prazo, quantidade de testemunhas, tempo para os depoimentos, etc. É importante ressaltar que muitos países criaram legislação semelhante às Leis de Segurança Nacional aplicada no Brasil. Essas leis tinham a função de proteger o país e foram criadas com o objetivo de contribuir na defesa contra os inimigos externos. Mas, contradizendo a regra, as Leis de Segurança Nacional eram utilizadas contra inimigos internos. 
riam contribuindo para uma vida social, livre e democrática. A construção de mitos, como a aversão ao comunismo e a maneira como isto se cristalizou no norte do Paraná, indica que o processo de transformação acompanha o declínio de todo Estado liberal: vigilância, perseguição e eliminação.

\section{ELEMENTOS PARA A COMPREENSÃO DO MITO POLÍTICO MODERNO}

A tentativa de teorização sobre o mito político moderno é necessária para abordar as correlações existentes entre a imaginação e a política, levando-se em consideração a análise do anticomunismo policial no norte do Paraná, sobre o período compreendido entre 1945 e 1953. Os momentos analíticos apresentados serão abordados conjuntamente de maneira a identificar as contradições do período proposto para análise.

Os estudos que debruçam sobre temas políticos têm se destacado nos últimos anos. 0 prestígio das pesquisas centradas nessa área é tributário da renovação das abordagens de pesquisas nas ciências sociais. A incorporação de elementos teóricos e metodológicos da antropologia permitiu a ampliação da compreensão do político para além das esferas institucionais, acrescentando atitudes, valores e ações de indivíduos como comportamentos a serem considerados nas abordagens políticas.

Outro aspecto a ser considerado é a "renovação" pela qual passou a História Política desde os anos 1970, concentrada na adoção das dimensões subjetivas do político. Este redirecionamento contribuiu para o aprofundamento dos estudos centrados nessa área. Rodrigo Patto Sá Motta ${ }^{10}$ identificou o "redespertar" da História Política em duas vertentes de pesquisa. Por um lado, uma renovação, ainda que tímida, dos enfoques sobre objetos tradicionais da política. Os adeptos dessa tendência se voltaram para a análise de práticas coletivas e comportamentos sociais, distanciando-se da perspectiva tradicional do político, mais concentrado nas elites e no Estado. Por outro lado, há esforços de pesquisadores interessados em apagar os últimos vestígios da História Política tradicional ou événementielle, enfocando suas pesquisas na exploração de novos objetos. Essa tendência visa encontrar as relações de poder na manifestação do inconsciente, nas representações e nos valores do comportamento humano. A identificação de duas grandes tendências dentro da "nova" História Política indica que o fenômeno de "renovação" não ocorreu de maneira unilateral e homogênea.

10 MOTTA, R. P. S. A história política e o conceito de cultura política. LPH Revista de História, Ouro Preto, n. 6, p. 92, 1996. 
Nesse contexto de mudanças teóricas, vários autores direcionaram a análise de seus estudos para o campo dos "mitos políticos". ${ }^{11}$ No caso do $\mathrm{PCB}$, verificou-se que a associação da militância revolucionária comunista ao ideal de liberdade fez que várias mentes de simpatizantes fossem povoadas por mitos. ${ }^{12} \mathrm{Em}$ contrapartida, as autoridades policiais imbuídas de simbologias afetas à brasilidade, garantia de propriedade individual, segurança nacional e ordem social, também encontraram nos mitos não apenas seus ideais de inspiração e legitimação de seu trabalho, mas formas de combater os supostos inimigos, dentre os quais figurava o comunismo. Porém, antes de adentrar nessa seara, faz-se necessário uma teorização deste conceito no sentido aqui atribuído.

Existem várias definições para o termo "mito", mas três delas se destacam. Primeiro, uma associação do mito às narrativas fabulosas e lendárias, geralmente de origem sagrada e que procuram explicar determinadas situações, como o surgimento do universo. ${ }^{13}$ Outra interpretação identifica o mito como uma camuflagem do real. Neste sentido, a ilusão e a mistificação seriam produtos imaginários, que não poderiam ter um fundamento legítimo. Por fim, a análise de Georges Sorel, mais flexível para as sociedades modernas. Segundo essa vertente, o mito possui caráter dinâmico, possibilitando a ação, como no caso do mito revolucionário. ${ }^{14}$

Os mitos políticos aqui abordados não se encaixam em nenhuma dessas categorias; na verdade, possuem elementos dos três conceitos apresentados. Trata-se de uma "narrativa que elabora uma explicação para a realidade social, contém uma série de mistificações e propõe um programa de ação" ${ }^{15}$

As construções mitológicas que vamos analisar procuram explicar como o discurso anticomunista construído pelas autoridades policiais tinha o objetivo de execrar os comunistas, utilizando como armas não apenas os acessórios típicos da violência, como a repressão e vigilância. A utilização de um vocabulário próprio, de um discurso embebido de exaltação da historicidade, integridade e brasilidade, acrescido de palavras como "ordem social"

11 GIRARDET, R. Mitos e Mitologias Políticas. São Paulo: Ed. Cia das Letras, 1987; ANSART, P. Ideologias, conflitos e poder. Rio de Janeiro: Zahar, 1990.

12 FERREIRA, J. Prisioneiros do mito: cultura e imaginário político dos comunistas no Brasil (1930-1956). Rio de Janeiro: Eduff; Mauad, 2002. p. 15.

13 ELIADE, M. Mito e realidade. São Paulo: Perspectiva, 1972. p. 7-10.

14 GIRARDET, op, cit. p. 13.

15 MOTTA, R. P. S. O mito da conspiração judaico-comunista. Revista de História, São Paulo, n. 138, p. 94 1998. 
e "bons costumes", também se apoia em mitos, os quais, somados, repeliam qualquer manifestação estrangeira, sobretudo de cunho soviético. ${ }^{16}$

Em toda sua complexidade, o mito político, aqui analisado na perspectiva anticomunista, pode ser visto como uma "narrativa legendária" que "exerce também uma função explicativa, fornecendo certo número de chaves para a compreensão do presente", bem como um "papel de mobilização" em função de seu caráter dinâmico. Para Girardet, é na união de três dimensões ("deformação", "explicação" e "mobilização") que a mitologia política se desenvolve e se consolida. ${ }^{17}$

Partindo do intuito de trabalhar com instituições políticas - como a Delegacia de Ordem Política e Social (DOPS-PR) e o Partido Comunista do Brasil (PCB) - pretende-se analisar as concepções mitológicas utilizadas pelas autoridades policiais no combate ao comunismo na região setentrional do estado do Paraná. O objetivo é analisar, por meio de documentos oficiais (relatórios, folhetos e similares), a linguagem coletiva que permitiu a comunicação no interior desse grupo, bem como a identificação de concepções mitológicas que fomentaram o combate, físico e teórico, entre autoridades policiais e comunistas.

O recorte temporal da pesquisa segue um eixo bem definido: o momento em que o setentrião paranaense foi marcado pela efervescente organização dos trabalhadores rurais na luta pela terra, como nos casos da Guerra de Porecatu (1948-1951) e por uma série de lutas ocorridas nas cidades em meio aos debates políticos sucedidos no final da Segunda Guerra, do processo de legalização do PCB e de sua posterior proscrição e dos constantes movimentos sociais urbanos. A atuação da polícia política neste período se configura ainda pelo controle político-cultural ou de qualquer forma de expressão que signifique ameaça à ordem social estabelecida. A ideia e o pensamento eram objetos de censura e de investigação. Nessa perspectiva, o órgão censor se apresentava mais eficaz. Entidades e instituições passaram a ser alvo de vigilância permanente, tornando-se objetos de investigação policial. Nessa perspectiva, concepções míticas, como a ideia de conspiração comunista e o discurso de brasilidade, tornaram-se fortes aliados das autoridades policiais na tentativa de repercutir no imaginário social a ideia do comunismo como um inimigo a ser abatido.

16 CHAUÍ, M. Brasil: mito fundador e sociedade autoritária. São Paulo: Editora Abramo, 2000. p. 37. 17 GIRARDET, op, cit. p. 13-14. 


\section{A IMAGINAÇÃO MÍTICA: O OLHAR DA DOPS EM RELAÇÃO AOS COMUNISTAS}

As décadas iniciais do século XX são marcadas pelo temor à subversão estrangeira, representada em um primeiro momento pelos anarquistas. A partir da Revolução de 1917 e da fundação do PCB em 1922, este "rótulo" foi atribuído aos comunistas, signatários de ideologias "exóticas", comumente denominadas "alienígenas" e consideradas responsáveis por contaminar os cidadãos brasileiros. Com o Estado Novo e o "apoio" de Vargas aos estadunidenses por ocasião da Segunda Guerra Mundial, os integralistas e imigrantes do eixo também entraram na lista dos profanadores do nacionalismo. Sem forças para persistir após a dura represália ao golpe de 1938, os adeptos de Plínio Salgado pereceram. Com o término da guerra e a diminuição considerável do fluxo teuto para o Brasil, os "partidários de Moscou" se tornaram o "inimigo número um" nas terras tupiniquins, em razão de sua periculosidade na desagregação da ordem social, sobretudo após a tentativa de assumirem o poder em 1935.

Na eminência da guerra fria e a disputa entre Estados Unidos e União Soviética, o mito da conspiração comunista que atingiu seu ápice com a "Intentona" de 1935 ressurge, adquirindo características de disputa internacional do poder. Em um momento anterior, entre 1917 e 1930, o comunismo foi considerado uma preocupação remota no Brasil. Sua doutrina aparentava ser um perigo eminente do velho mundo, particularmente do leste europeu. Em função deste distanciamento, tornou-se prática recorrente tratá-la como uma ideia "alienígena", presente na realidade de outros países, embora grupos operários organizados, greves e a fundação do Partido Comunista do Brasil, em 1922, fossem motivos de preocupação para algumas autoridades.

Desde o início da Era Vargas em 1930, houve a intensificação do papel da polícia, preocupada em combater as "ideologias exóticas" como o fascismo, nazismo, integralismo e comunismo. As tentativas de aproximação com tais vanguardas extremistas praticamente deixaram de existir com o rompimento da relação do governo brasileiro com a União Soviética e, em seguida, com a declaração bélica ao Eixo ${ }^{18}$ durante a Segunda Guerra Mundial. Para Elizabeth

\footnotetext{
18 Opositores dos Aliados na Segunda Guerra Mundial, os países do Eixo, encabeçados pela Alemanha de Adolf Hitler, pela Itália de Benito Mussolini e pelo Japão de Tojo Hideki e do Imperador Hirohito, eram também conhecidos como "Eixo Roma-Berlim-Tóquio" por seus inimigos. Além dessas três nações principais, faziam parte outras menores como a Bulgária, Hungria e Romênia. Os países do Eixo saíram derrotados na Segunda Guerra, fato que chegou ao seu apogeu na invasão à Alemanha pelos Aliados e pelo suicídio de Hitler, ao passo que no Japão, Hiroshima e Nagasaki foram bombardeadas e praticamente sumiram do mapa.
} 
Cancelli, nesse momento, "o governo passara a ser o Estado, e a polícia, o mais importante dos órgãos de poder na sociedade, uma vez que personificava o braço do executivo da pessoa do ditador e de um novo projeto político" ${ }^{19}$

A definição de "subversivos" nem sempre estava muito explícita. A díade subversão/repressão perpetuou no imaginário dos órgãos de segurança, a ponto de formar uma "cultura policial". Essa, por sua vez, assumiu contornos mais nítidos a partir de 1946, quando a Constituição vigente garantia, em seu artigo 18, que o sistema de segurança assumiria características próprias em cada Estado da Federação: "cada Estado se regerá pela Constituição e pelas leis que adotar, observados os princípios estabelecidos por esta Constituição". O parágrafo $2^{\circ}$ do mesmo artigo define que "os Estados reservam todos os poderes que, implícita ou explicitamente, não lhes sejam vedados por esta Constituição". Entre os poderes permitidos estavam o de organizar e estruturar o sistema policial. Criou-se, portanto, um cenário onde a polícia política conseguiu se fortalecer e adquiriu autonomia operacional em relação ao governo.

Valendo-se dessa liberdade de atuação, as autoridades policiais, enquanto partidárias do proibicionismo, procuravam hierarquizar ideias no intuito de purificar a sociedade. Apesar da autonomia concedida aos aparatos policiais a partir da Constituição de 1946, é importante ressaltar que durante o Estado Novo, criou-se uma rede de união e de informação em todo o país, ampliando o espaço de controle da polícia política para além das fronteiras. Entre 20 de outubro e 5 de novembro de 1936, foi realizado no Rio de Janeiro o Congresso dos Chefes de Polícia, que tinha o intuito de aproximar as polícias estaduais "tendo em vista o aperfeiçoamento do trabalho de repressão ao comunismo". ${ }^{20}$

A interferência de Vargas nos sistemas de segurança estaduais se fez sentir em 1937 com a criação de delegacias especializadas na questão social. Com a Lei $n^{\circ} 177$, de 15 de março de 1937, o Paraná reestruturou suas delegacias, as quais se dividiram em: Delegacia Auxiliar, Delegacia de Ordem Política e Social, Delegacia de Segurança Pública e Delegacia de Vigilância e Investigações. As competências e atribuições das Delegacias Especializadas, incluindo a de Ordem Política e Social foram fixadas em 3 de abril de 1937, por meio da Portaria $n^{\circ}$ 26, publicada na gestão do Chefe de Polícia Dr. Roberto Barroso. ${ }^{21}$

19 CANCELLI, E. 0 mundo da violência: a polícia da Era Vargas. São Paulo: Edumb, 1993. p. 47.

20 MOTTA, R. P. S. Em guarda contra o perigo vermelho: São Paulo: Perspectiva-Fapesp, 2002. p. 57.

21 PRIORI, A. Polícia política e sociedade: funcionamento e métodos de ação do DOPS/PR (1930-1964) - notas de pesquisa. Relatório (Pós-doutorado em História). Programa de Pós-Graduação em História, 
Ainda que se tratasse de delegacias institucionalmente separadas, o trabalho delas sempre se realizava de forma conjunta. 0 núcleo geral de coordenação das atividades estava centrado em Curitiba, capital do estado, mas, em todo o Paraná foram estabelecidas Delegacias Regionais, as quais tinham o importante papel de comunicar todas as suas atividades. Mesmo com a instalação de uma Delegacia Regional em Londrina, é importante salientar que a contribuição mútua entre essas esferas do setor policial ultrapassava o âmbito criminal e abrangia questões políticas, sociais e até mesmo morais, como na defesa dos "bons costumes", da família, da propriedade e da "ordem pública".

Seguida da estruturação de Delegacias Regionais, a década de 1940 também foi palco da organização dos trabalhadores rurais, sobretudo sintetizada na luta pela terra e por uma luta política cotidiana nas cidades, seja pelos debates políticos no final da Segunda Guerra, do processo de legalização do PCB e sua posterior proscrição ou dos constantes movimentos sociais urbanos. Todas essas mudanças foram acompanhadas pelo olhar atento da DOPS, a qual, por meio de seus agentes, hierarquizava a população local, definindo-os como "bons" ou "maus" elementos. Em um documento de 1949, um agente policial ressaltava a periculosidade da região de Londrina, atentando para a diversidade de pessoas que ali se fixaram e como isso poderia ser um cenário proveitoso para "questões políticas", principalmente para a ação de comunistas:

Há muita influência de aventureiros nessa cidade (...). Londrina necessita de um bom quadro de agentes competentes, para fazer frente, com eficácia, aos problemas policiais, pois o movimento e a afluência de elementos de toda a espécie é desusado em todo o município. ${ }^{22}$

Aliás, o trabalhador, sobretudo o homem do campo, era visto como facilmente ludibriável. Tal visão, alimentada pela DOPS, pode ser mais bem compreendida com a explosão da Revolta de Porecatu, que ocorreu entre 1948 e 1951, no norte do Estado. Desde 1946, 1500 famílias de posseiros, ocupando terras devolutas no norte do Paraná, especificamente em Jaguapitã, Guaraci, Centenário do Sul e Porecatu, estavam sendo ameaçadas de desapropriação, pelo fato de o governo estadual ter doado as terras, já ocupadas pelos posseiros, a grandes proprietários. Em meio à turbulência, houve reação violenta de ambas as partes e os posseiros formaram grupos armados

Universidade Federal de Minas Gerais, Belo Horizonte, 2011. p. 6.

22 FUNDO DOPS/DEAP. Relatório n 0857/105. 
para se defender. No final do ano de 1950, o PCB se mobilizou para participar do litígio apoiando os camponeses. Com a influência comunista houve a eclosão do que a pequena historiografia existente sobre o assunto consagrou como a "Revolta Camponesa de Porecatu". ${ }^{23}$

Fazendo oposição ao movimento, a polícia política tentava utilizar todos os mecanismos existentes para combatê-lo, alertando o país da periculosidade do episódio. Em julho de 1951, o diretor da Divisão Polícia Política e Social, major Hugo Behtlem, recebeu um relatório do delegado de Ordem Política e Social do Paraná, Celso Nicolau dos Santos ${ }^{24}$, no qual constavam informações referentes ao esforço empenhado pelas autoridades a fim de reprimir a manifestação em Porecatu. Nele, o delegado da DOPS-PR se refere ao levante como o local onde o "desentendimento se verifica" e "um desajustamento se constata", atribuindo ao órgão comunista o símbolo do afloramento natural das "imperfeições da sociedade humana", além de acusar o partido de sempre estar presente "para explorar, para agitar e para mais fundo cavar na discórdia".

A persistência do partido em desprezar a decisão tomada pelo Tribunal Superior Eleitoral (TSE), o qual, em 7 de maio de 1947, determinou a proscrição do PCB, seguida da cassação dos parlamentares eleitos por sua legenda, realizada em 7 de janeiro de 1948 por meio de votação do Congresso Nacional, deixava a polícia política alarmada com o fato dos comunistas pretenderem "solapar nossa organização política, social e econômica". ${ }^{25}$ Tal temor remete ao fantasma da Revolução de 1917, em função dos bolcheviques assumirem o poder na União Soviética, e, consequentemente, à tentativa semelhante ensaiada pelos comunistas no levante ocorrido em novembro de 1935, por Prestes e seus signatários.

Além do episódio da Intentona Comunista, em 1935, outro momento no qual o PCB abraçou uma postura de caráter demasiadamente revolucionária foi logo após a sua cassação, em 1947, período que se iniciava a guerra fria, e com ela, o dinamismo no combate à doutrina comunista. Sendo assim, em função de influências externas, o partido teve que radicalizar sua postura, pondo em prática uma política já anunciada por Prestes entre os anos de

$23 \mathrm{Na}$ literatura especializada sobre o assunto, é válido conferir os seguintes trabalhos: PRIORI, Angelo. A Revolta Camponesa de Porecatu: a luta pela defesa da terra camponesa e a atuação do Partido Comunista Brasileiro (PCB) no campo (1942-1952). Tese (Doutorado em História) - Faculdade de Ciências e Letras Universidade Estadual Paulista. Assis - SP, 2000. Editada em livro: PRIORI, Angelo. O levante dos posseiros: a revolta camponesa de Porecatu e a ação do Partido Comunista Brasileiro no campo. Maringá: Eduem, 2011. 24 FUNDO DOPS/DEAP. Pasta Delegacia de Polícia de Londrina, n544d, top: 61. p. 146-147. 25 FUNDO DOPS/DEAP. Pasta Delegacia de Polícia de Londrina, nº 544d, top: 61. p. 146. 
1947 e 1948, a qual apontava a criação de uma Frente Democrática de Libertação Nacional (FDLN). Essa postura radical foi confirmada com a publicação do Manifesto de Agosto de 1950 e no IV Congresso do PCB, ocorrido em 1954.

A liderança do PCB entendia que deveriam enfatizar seu trabalho nas regiões que agregassem grande parte de camponeses. Sendo assim, o partido decidiu concentrar suas atividades nos estado de São Paulo, no norte do Paraná e no Triângulo Mineiro ${ }^{26}$. Com a proposta de "esquerdizar" sua linha política, o PCB pós-1950 tinha a ideia de transformar Porecatu em "uma base permanente de luta armada e estendê-la, formar ali uma espécie de território libertado. Essa era a idéia". ${ }^{27}$

Temendo a perda do poder aos comunistas, como ocorreu na Revolução de 1917 na União Soviética, a polícia política trabalhou no amoldamento de um imaginário social, opositor aos comunistas, com o objetivo de tentar contê-los. Em consonância com Bronislaw Baczko ${ }^{28}$, a construção de uma mentalidade coletiva corresponde ao exercício do poder e a legitimação do discurso governista. É nessa intenção, segundo Baczko ${ }^{29}$, que as "ciências humanas punham em destaque o fato de qualquer poder, designadamente o poder político, se rodear de representações coletivas. Para tal, o domínio do imaginário e do simbólico é um importante lugar estratégico". Ainda assim, o imaginário edificado por sociedades e grupos, mesmo que traga elementos novos, possui vínculos com tradições mais antigas. As imagens que se formam em um cenário específico não estão descoladas da realidade e remetem a reminiscências históricas. No caso em questão, o alerta policial se referia à possibilidade de reviver momentos históricos em que os comunistas, por meio da ação revolucionária, classificada como "violenta", destruíram a ordem social vigente para implantar sua doutrina.

Em consonância com Roger Chartier, as percepções do social estão repletas de discursos carregados de sentido. Longe de serem neutros, eles produzem "estratégias" e "práticas" que buscam legitimar certa conduta ou projeto reformulador. Por isso, a "luta de representações" convive em situação de competição constante, desafio do qual emana o poder. Nesse embate,

26 PRIORI, A. Movimentos sociais no campo: perspectiva de abordagem e análise historiográfica. In: PELEGRINI, S. C. A.; ZANIRATO, S. H. (Org.). Narrativas da pós-modernidade na pesquisa histórica. Maringá: Eduem, 2005. p. 155.

27 ARQUIVO PESSOAL DE TERESA URBAN. Entrevista com Jacob Gorender. São Paulo, 19 mar. 1985.

28 BACZKO, B. A imaginação social. In: LEACH, Edmund et al. Anthropos-Homem. Lisboa: Imprensa Nacional/Casa da Moeda, 1985. p. 296-332.

29 Ibidem. p. 297. 
um grupo tenta impor sua visão de mundo e seus valores, consagrando sua superioridade e domínio. Assim, a "objetividade das estruturas" (de construção quantitativa e minuciosa das sociedades em sua vivência real) e a "subjetividade das representações" (dirigidas às ilusões e discursos desconexos) não podem sofrer uma hierarquização. Ambas se complementam na afluência do levantamento real e da consubstanciação de "utopias" e "mitos". Tais representações assumem o papel de base dos discursos, ainda que coletivos, somente quando "comandam atos" e geram a prática. ${ }^{30}$

A lógica do discurso mítico estaria, portanto, na repetição, associação e combinações que realizam na imaginação coletiva. Ao mesmo tempo, essas combinações obedecem a uma determinada ordem e "inscrevem-se em uma 'sintaxe', para retomar a expressão de Claude Lévi-Strauss: em outros termos, é agrupado em séries idênticas, estruturados em associações permanentes que se apresentam os elementos construtivos da narrativa que elas compõem". ${ }^{31}$

Formou-se, a partir de então, um conjunto de representações que tinham como objetivo a luta contra Prestes e seus seguidores. Este ideário é denominado imaginário anticomunista, corrente de pensamento que foi incorporada ao Estado, instituições sociais e mesmo na concepção de indivíduos ou grupos desvinculados do governo, embora possuísse diferentes matizes. Tal bandeira se fez presente nas lutas políticas, discursos e manifestações, mas nem sempre ocorreram na mesma intensidade e de forma homogênea. Um dos principais momentos em que a bandeira anticomunista foi empunhada se circunscreve entre 1945 e 1953, quando após um pequeno intervalo legal, o PCB foi novamente proscrito em 1947, e o pensamento autoritário se acirrou com a publicação da Lei de Segurança Nacional de 1953, a qual, segundo a forma como foi redigida, deveria legislar em torno da "defesa do país, da nação, contra a agressão estrangeira”. No entanto, para a segurança nacional não existia uma distinção nítida entre "inimigo externo" ou "interno". Seguindo uma lógica anticomunista, principalmente após as mudanças ocorridas com a Segunda Guerra Mundial, quando o Brasil, a exemplo de outras nações se alinharam aos Estados Unidos, tratou de investir no sistema de segurança. Tal preocupação culminou na formação da Escola Superior de Guerra (ESG), em 1949. Essa, por sua vez, seguia uma orientação estadunidense e possuía o objetivo de formular uma nova doutrina para a

30 CHARTIER, R. A história cultural: entre práticas e representações. 2. ed. Portugal: Algés, 2002. p. 17-18. 31 GIRARDET, op, cit., 1987. p. 17. 
segurança nacional, pautada no embate ao comunismo internacional, assim, se estruturou o sistema de vigilância de fins do governo Eurico Gaspar Dutra.

A visão mítica em relação ao comunismo contaminou vários setores da sociedade, e a polícia política foi um deles. Principalmente a partir do fim do Estado Novo, momento mais conhecido como "democrático", os setores policiais não somente se portaram como parceiros das forças políticas como, muitas vezes, agiram de forma independente reutilizando a memória mítica para neutralizar a disputa em torno da política interna brasileira, em nome da luta simbólica contra a disseminação do comunismo na América Latina. A instabilidade enraizada desde o início da guerra fria criou um ambiente propício para a propagação de mitos. A recorrência a esses modelos teóricos era, na verdade, uma tentativa de buscar um elemento fornecedor de sentido, mesmo que seu uso para as explicações de mudanças seja um eterno desafio à razão. ${ }^{32}$

Para a polícia política, o seu papel era manter a ordem social, ou seja, frear o avanço vermelho como forma de impedir que as revoluções de 1917, na União Soviética, e o levante de 1935, no Brasil, se repetissem. No setentrião paranaense, a atuação comunista na Revolta de Porecatu teria exigido uma ação enérgica. Nessa região, segundo o relatório do delegado Celso Nicolau dos Santos, o PCB teria vivido "à vontade e pode daqui dirigir e arregimentar bandos armados que, intitulados de 'Posseantes de Porecatu', constituíram um fato criminoso de repercussão nacional". ${ }^{33}$ Segundo Angelo Priori, ${ }^{34}$ a polícia política se fez presente na região litigada apenas quando os camponeses estavam organizados e os militantes do PCB participavam do confronto. Tal situação representava um paradoxo, já que a DOPS realizava diligências no norte do Estado desde a década de 1930. A ação tardia se explicava pelo fato de a polícia política não possuir um preparo adequado para lidar com insurreições camponesas. O autor reitera essa afirmação ao considerar a demora da atuação da DOPS como uma estratégia do órgão, que chegou a atuar dez meses no conflito, desarticulando, ao fim, o movimento insurrecional camponês após este curto período de presença.

A linguagem policial responsabilizava os pecebistas por ações desse tipo, mas também desqualificava os grupos que mesmo não se declarando assumidamente comunistas participavam de mobilizações encabeçadas pelo

32 KALAKOWSKI, L. A presença do mito. Brasília: UnB, 1981.

33 FUNDO DOPS/DEAP. Pasta Delegacia de Polícia de Londrina, n 544d, top: 61, p. 146.

34 PRIORI, op, cit., 2000. p. 263-264. 
PCB. "Gente da roça", "polichinelos de Porecatu", "ignorantes" e "intrusos" são apenas algumas expressões do vocabulário policiesco utilizado para reprovar as atitudes de pessoas que coligavam seus interesses aos comunistas ou se deixavam levar por eles. Longe de ser objetiva, a análise policial remete a uma visão parcial. Os posseiros não passavam de "agitadores" e o litígio por terras nada mais era que um "caso" que necessitava de uma ação enérgica para reestabelecer a "ordem". ${ }^{35}$

A movimentação comunista se sustentava no temor à desestruturação do poder centralizado, à fixação de uma "quinta coluna vermelha" e ao provável isolamento do norte do Paraná em relação ao país. Na visão da DOPS, o comunismo cogitava "aumentar os hiatos, acrescer as dissenções e estabelecer um clima de desentendimento que enfraqueça o Estado, desmoralize a sociedade, solape a economia e lhes propicie meios para a conquista revolucionária do poder e o estabelecimento de mais uma dessas infelizes e caricatas 'democracias populares'." 36

O caráter internacional dos partidos comunistas era outro entrave para o ideal de brasilidade alimentado pelos setores mais conservadores. A leitura feita pela polícia política era de uma mundialização do comunismo pautado na união entre os trabalhadores, postergadas as diferenças nacionalistas, discurso considerado típico da sociedade burguesa. Este foi, sem dúvida, um dos principais pontos conflitivos do comunismo e um dos argumentos utilizados para frear a expansão do PCB. A proscrição do partido em 1947 é um exemplo bastante elucidativo, dado que o Supremo Tribunal Federal alegou que o PCB seria uma extensão do Partido Comunista da União Soviética (PCUS) no Brasil, portanto, um braço estrangeiro atuando como organismo político. A declaração de Prestes publicada no jornal comunista Tribuna Popular, de 16 de março de 1946, na qual ele afirmou que se houvesse uma guerra entre Brasil e União Soviética apoiaria esta última, foi interpretada como uma manifestação antipatriótica. ${ }^{37} \mathrm{~A}$ grande repercussão que tiveram as afirmações de Prestes foi utilizada para demonstrar que o PCB era um órgão de representatividade soviética no Brasil. A linguagem simbólico-ideológica dos militares e das forças governistas, associando o PCB com a União Soviética,

35 FUNDO DOPS/DEAP. Pasta Delegacia de Polícia de Londrina, n 544d, top: 61, p. 146-148.

36 Ibidem. p. 148.

37 Questionado por um jornalista sobre qual seria a posição dos comunistas caso o Brasil iniciasse uma guerra contra a URSS, Prestes afirmou: "Faríamos como o povo da resistência francesa, o povo italiano que se ergueram contra Petain e Mussolini. Combateríamos uma guerra imperialista contra a URSS e empenharíamos armas para fazer resistência em nossa Pátria". ARQUIVO PÚBLICO DO ESTADO DO RIO DE JANEIRO - Fundo DPS. Jornal Tribuna Popular, 16 mar. 1946. 
começou a ser feita desde 1946, quando entrou em pauta uma determinação da Nova Lei de Segurança Nacional, que permitiria reformar compulsoriamente os militares que pertenciam a partidos antidemocráticos.

Explícito o alinhamento do Brasil aos Estados Unidos, governado naquele momento por Harry Truman, o rompimento das relações com a União Soviética, em outubro de 1947, teve como consequência interna a ilegalidade do PCB e a cassação dos mandatos dos congressistas comunistas. A partir de então, o Exército, baluarte do nacionalismo e das honras à pátria, se envolveu de forma mais intensa e aberta na luta contra o PCB, acionando as localidades militares brasileiras no dia em que o registro do partido foi cancelado.

A suposta negação à pátria, da maneira como foi interpretada a declaração de Prestes, soou no interior do congresso. Acusando os militantes comunistas e afins de "agentes de Moscou", já nos últimos dias de março de 1946, Edmundo Barreto Pinto, deputado do Partido Trabalhista Brasileiro (PTB), encaminhou o pedido de cassação do registro do PCB, alegando que este era uma extensão do partido internacional comandado pelos soviéticos, estimulador da luta de classes, antidemocrático e que seria favorável à União Soviética no caso de uma guerra com o Brasil.

Tais acusações pesaram na manutenção do registro do PCB que acabou cancelado em 1947, após a instauração de sindicância determinada pelo Tribunal Superior Eleitoral (TSE). Também foram proscritos os mandatos dos parlamentares comunistas, em janeiro de 1948. Assim, a ideia de complô nutria a associação que a cultura comunista fazia da União Soviética, como a "pátria do socialismo", a ser defendida a todo o momento. A internacionalização dos comunistas contrastava com o nacionalismo e intimidava os setores conservadores, motivando-os a criar ícones que remetessem à ideia de patriotismo.

Para Girardet, ${ }^{38}$ o mito constitui "ele próprio um sistema de crença coerente e completo". Uma vez legitimado, o mito ou um conjunto de mitos ("constelações míticas") se desenvolvem livremente, podendo ser classificados à "direita" e à "esquerda", ao sabor das oportunidades de cada momento. Os papeis atribuídos a determinados mitos podem variar de acordo com o tempo e espaço, segundo debates ideológicos e embates partidários. Fazendo uso da criação de mitos políticos para legitimar a ideia de nação, círculos conservadores teceram discursos reprovando a interferência externa, sobretudo no que tange à ação de organismos considerados internacionais e vinculados aos soviéticos ou a qualquer país comunista.

38 GIRARDET, op, cit. p. 11-12. 
Em nível estadual, a DOPS articulou uma rede de informações com a criação de novas unidades, as quais se multiplicavam no rastro da expansão vermelha. Adotou um discurso saneador e vigilante, cujo alvo principal no pós-guerra fria eram os militantes comunistas. A construção da concepção de "subversivos" estava atrelada aos "causadores da desordem". Estes variavam de acordo com o período histórico, podendo ser os anarquistas, comunistas, vadios, mendigos e outros grupos sociais passíveis de infringir as regras ditadas por superiores. Assim, o mito da conspiração assume diferentes roupagens, elegendo inimigos de naturezas diversas, tanto internos quanto externos. Os comunistas, de forma singular, se destacaram como subversivos a partir de 1935, por meio da tentativa frustrada de ocupar o poder, mas foi entre 1946 e 1947 que receberam atenção especial pelos órgãos policiais. Nesse período, o PCB adquiriu importância considerável, conseguindo se infiltrar no centro de vários sindicatos operários, além de contabilizar votos para as eleições estaduais e complementares em janeiro de 1947 para o congresso. Em função dessa força crescente, o governo Dutra optou pela repressão. Um procedimento legal incluso na Constituição de 1946 afirmava que partidos considerados "antidemocráticos" deveriam ser impedidos de atuar livremente no âmbito político..$^{39}$

Após a proscrição do PCB em 1947, o governo Dutra autorizou a cassação, em 1948, de seus parlamentares, iniciando a "repressão macarthista de caça às bruxas contra todas as pessoas e instituições tidas como subversivas e deletérias à ordem pública". Por mais que o sentido de "subversivo" se remetesse aos comunistas nesse contexto, é notório que todos poderiam ser suspeitos. A repressão política "politiza" a luta contra o crime, transformando "todos os vadios em ladrões, assaltantes e arrombadores; prostitutas, menores nocivos, revolucionários" em potenciais embusteiros e em criminosos os "políticos capazes de serem utilizados pelos agitadores". ${ }^{40}$

No Paraná, Moysés Lupion foi eleito Governador do Estado nas eleições de 1946. No entanto, as alterações nos organismos de segurança apenas seriam sentidas um ano depois. Com a Constituição Estadual, promulgada em 12 de julho de 1947, o aparelho policial adquire certa autonomia, condizente com o parágrafo $2^{\circ}$ da Constituição Nacional de 1946. A Carta Magna do Paraná definiu, em seu artigo 171, que a função da Polícia Civil estaria direcionada nas "garantias individuais, da segurança e da tranquilidade pú-

39 SKIDMORE, T. Brasil: de Getúlio a Castelo (1930-1964). São Paulo: Cia das Letras, 2010. p. 100. 40 COSTA, A. M. da. O Dops e os trabalhadores. Cadernos da UPT, Curitiba, ano 1, nº 1, 1993, p. 9-10. 
blicas e prestar sua colaboração para a perfeita eficiência da justiça repressiva". Nesse caso, a própria legitimação da violência se encontra estampada na permissão da chamada "justiça repressiva". No entanto, quando o discurso policial é divulgado em meios de comunicação, com vultosa circulação entre os círculos populares, a fala adquire novas roupagens e assume versões diferenciadas.

O periódico "Magazine Político", por ocasião da visita a Londrina de Albino Silva, Chefe de Polícia do Paraná entre os anos de 1951 a 1952, afirma que a questão das disputas por terras na região era mediada pela polícia política com a mais absoluta cautela, longe do "apelo à violência". Nessa mesma reportagem, uma reprodução da fala de Albino Silva salienta que a "ação policial, prudente e cautelosa, só pode ser bem recebida, pois ela se exerce no sentido da ordem pública e na garantia de segurança policial". o periódico, saindo em defesa da atuação policiesca, confere ao que chama de "bandoleiros" e "capitães do mato" as ações de brutalidade, acrescentando que esses grupos "teimam em não reconhecerem a proscrição de tais métodos, incompatíveis com nossos foros de povo civilizado" ${ }^{41}$

Sagração da natureza, civilidade, valorização do governante e engrandecimento da história podem ser identificados como os pilares do que Marilena Chauí afirma ser o "mito fundador". ${ }^{42} \mathrm{O}$ culto à natureza está representado na redenção da terra, sua fertilidade e riqueza. Dele emerge a ideia de um país livre de desgraças naturais (furacões, terremotos etc.) e de uma beleza sem tamanho. Na valorização do governante predomina o elogio que se faz em relação ao Estado e também aos setores policiais como uma extensão deste. Trata-se de uma autopropaganda com o intuito de mostrar as tradições democráticas e a figura do governante preocupado com a questão social, atrelada ao ideal de uma sociedade justa e segura. 0 engrandecimento da história se remete aos "bravos conquistadores" que desbravaram o "sertão" e sua relação com os indígenas e a natureza garantiriam uma sobrevivência harmônica e feliz.

A expressão mais marcante do "mito fundador" foi o que Chauí chamou de "verde-amarelismo". Desde o período colonial, o Brasil se formou essencialmente agrário, e as elites coloniais se agarraram a este ideal durante todo o Império até a República Velha. Durante a década de 1920 o "verde-amarelismo" passou a dividir suas atenções com outro discurso: o

41 FUNDO DOPS/DEAP. Pasta Delegacia de Polícia de Londrina, n 544d, top: 61, p. 116.

42 CHAUÍ, op, cit. p. 37. 
direcionado ao "povo brasileiro". Na visão de Chauí, é a partir de Vargas que o "verde-amarelismo" assume tons mais nítidos, assegurando que "aqui não há lugar para a luta de classes e sim para a cooperação e colaboração entre o capital e o trabalho, sob a direção do Estado" "43 a percepção de um povo fiel, desprovido de preconceitos e garantido por um futuro promissor conviviam com a indignação de alguns grupos, a truculência policial e a proscrição de direitos políticos garantidos constitucionalmente. Tais representações, em vez de se chocarem, se complementavam, projetando a imagem de uma sociedade fraterna, imbuída de elementos positivos.

Muitos movimentos, como o dos comunistas, procuraram questionar a unidade transparecida pelo "mito fundador". No entanto, tal construção mítica sustentou um "semióforo", ou seja, a apropriação que o poder político representado pelo Estado fez desse discurso, tornando-o instrumento de verdade absoluta e, ao mesmo tempo, um mecanismo para repreender seus opositores. Somando desigualdades e conflitos, da forma mais natural possível, o "mito fundador" neutraliza as ações do povo como representantes sociais, delegando o papel de transformação do país apenas ao Estado, a Deus - representado pelo culto à religião dominante - e à natureza (exaltação da beleza). Na penumbra do "mito fundador" aparecem os contornos de uma sociedade amordaçada, mas que não se pensa como tal. Distraída com o culto à história, ao Estado e à natureza, a sociedade, que se ajuíza democrática, em função de eleições e outros organismos de representação, fica imersa e refém de mitos cujos objetivos são o conformismo e o controle.

A análise de documentos policiais, periódicos de diversas naturezas, material subversivo apreendido, depoimentos e relatórios permite a visualização de inúmeros elementos simbólicos que, frutos de pontos de vista diferentes subsidiavam o imaginário político brasileiro do século XX. “Ambos os lados - tanto o ordenador/repressor como o revolucionário/sedicioso geraram rituais, alimentando mitos". ${ }^{44}$

A associação da militância revolucionária com o comunismo, introduzindo a ideia de "perigo vermelho" foi fator pujante para a suposta conspiração dos comunistas, a qual, nessa perspectiva, pretendia instaurar a ditadura do proletariado. Por outro lado, tal fenômeno poderia ser interpretado como uma derivação do anticomunismo construído pelo ideário conservador. A análise do mito da conspiração comunista como uma complementação do

43 Ibidem. p. 37.

44 CARNEIRO, M. L. T. Livros proibidos, ideias malditas: o DEOPS e as minorias silenciadas. São Paulo: Estação Liberdade/Arquivo Público do Estado/SEC, 1997. p. 27. 
anticomunismo contribui para a compreensão de mudanças estruturais no setor policial, bem como de uma sociedade educada assimilar discursos que aspiravam à brasilidade.

Combinando uma vigilância constante com o fortalecimento da autonomia operacional da polícia política no norte do Paraná a partir do fim do Estado Novo, a DOPS utilizou os meios mais variados para alertar a sociedade sobre o perigo "alienígena". o objetivo não era simplesmente ressaltar a ação negativa do comunismo na região, mas traçar estratégias na tentativa de conscientizar o coletivo sobre as ações nocivas da doutrina vermelha.

Um desses mecanismos, o qual compõe o "mito fundador", foi o discurso da brasilidade, ou seja, da democracia liberal como redentora do mundo capitalista e sendo o único meio de levar a liberdade para todos os homens. No entanto, para se estabelecer, a brasilidade deveria eliminar os "agentes do mal" ou "agentes de Moscou", organizados em um partido que era visto como a extensão do comunismo soviético no Brasil e, portanto, um organismo internacional. Este, por sua vez, feria tal discurso, pautado no patriotismo, integridade familiar, liberdade, segurança, moralidade e democracia. Tratava-se, portanto, de uma "patologia" que estava contaminando a boa convivência dos brasileiros. 0 antídoto para essa anomalia era expurgar os inimigos do Estado, principalmente os comunistas. A rejeição poderia ser notada em discursos inflamados, os quais, ao serem absorvidos pela população, os transformavam em "agentes", assumindo olhos e ouvidos da vigilância e representando uma extensão da repressão corporificada por meio da denúncia. A acusação contra a profanação de símbolos nacionais ou a idolatria de insígnias estrangeiras eram as mais comuns, sobretudo se realizadas em ambiente público.

Em uma correspondência anônima, cuja identificação aparece como "Um amigo de Londrina, do Estado e, sobretudo, do Brasil", enviada ao Chefe de Polícia de Curitiba em 17 de maio de 1954, são visíveis as manifestações de repulsa em relação ao comunismo e evidentes alguns elementos que identificam a brasilidade. Nela, o remetente sentencia:

O desplante dos vermelhos, em Londrina, é de estarrecer: sabia V. Excia., que há pouco tempo os vermelhos, num domingo, hastearam a bandeira soviética em plena Prefeitura, e somente foi percebido às 11 horas de domingo, depois da saída da missa?

Sabe V. Excia. que as bancas de jornais, vendem, ostensivamente, jornais, revistas e livros exclusivamente comunistas? 
Mande certificar-se, por exemplo, da banca que se situa na praça defronte a filial de Hermes Macedo S.A. em LONDRINA. ${ }^{45}$

O fato de a bandeira soviética aparecer içada em um ambiente público significa, na leitura do delator, um desrespeito aos símbolos brasileiros. Em vez de a bandeira nacional ser estendida, optou-se por uma insígnia de outro país, agravada por ser a pátria do comunismo. Além do mais, a acusação foi remetida diretamente à DOPS da capital paranaense, talvez como uma manifestação de descrença na polícia política local. o descontentamento em relação ao serviço prestado pela delegacia de Londrina parece transparecer na indignação manifestada ao fato de a bandeira soviética ser notada tardiamente, apenas após a missa. Os indícios de que periódicos e obras comunistas estavam sendo vendidos livremente na cidade sinalizavam a falta de fiscalização, a qual era competência da Delegacia Regional de Londrina.

Muitas vezes, questões ideológicas e pessoais se mesclavam, fornecendo motivos para a delação. ${ }^{46}$ Ao indicar um endereço específico de uma banca no último parágrafo da carta, é bem provável que seu remetente teria outras intenções ao denunciá-lo. Como se trata de uma correspondência anônima, breve e sem elementos adicionais que poderiam enriquecer a interpretação, qualquer afirmação se torna arriscada. No entanto, a acusação a um estabelecimento específico levanta dúvidas. Teria o delator se aproveitado da perseguição aos comunistas para prejudicar um provável desafeto ou concorrente? No conjunto de fontes analisadas, ${ }^{47}$ não foram encontradas qualquer resposta ou referência à carta, o que não permite a confirmação dessa hipótese. Ainda assim, a correspondência ressalta elementos da brasilidade e rejeição de londrinenses a elementos simbólicos que remetem ao comunismo ou à União Soviética, o que não pode ser desprezado, principalmente quando se trata de uma denúncia externa ao ambiente policial.

Invocando emblemas, o relatório de 1951, com autoria creditada ao delegado de Londrina na época, Celso Nicolau dos Santos, destaca que enquanto na mão esquerda os comunistas "ferem com foice e martelo, sustentam, na direita, a carta constitucional do país". A primeira menção diz respeito ao símbolo internacional do comunismo e, ao mesmo tempo, uma insígnia nacional da União Soviética. Os objetos que ilustram a bandeira so-

45 FUNDO DOPS/DEAP. Pasta Delegacia de Polícia de Londrina, n 544d, top: 61, p.111.

46 FLORINDO, Marcos Tarcísio. O serviço reservado da Delegacia de Ordem Política e Social de São Paulo na Era Vargas. São Paulo: Editora Unesp, 2006. p. 129.

47 FUNDO DOPS/DEAP. Pasta Delegacia de Polícia de Londrina, n 544d, top: 61. 
viética não se referem basicamente a instrumentos de trabalho. Observados em uma ótica de simbolização, remetem à ideia de aliança firmada entre trabalhadores do campo e da cidade, uma simbiose entre labutadores e socialismo que ganhou proporções mundiais. O sentido de lesão associada aos pecebistas remete à ideia de desordem. Longe de cumprirem as leis nacionais e teimando atuar na clandestinidade, desde 1947, os comunistas insistiam em exigir "apenas os direitos, procurando sistematicamente ignorar e desrespeitar os deveres que a Constituição Federal lhes impõe". ${ }^{48}$

As críticas atribuídas pelos agentes da DOPS aos comunistas não eram oriundas somente da prática revolucionária, representada por suas atuações no norte do Paraná na Revolta de Porecatu e em várias campanhas realizadas nas cidades da região. No relatório, Celso Nicolau dos Santos relata a periculosidade ideológica que representavam os integrantes do PCB. Em sua acusação, o delegado afirma que o partido utilizava uma "série de rótulos, cada qual mais inocente, convergindo todos para dupla finalidade de iludir os incautos e mascarar suas atividades subversivas exigidas por lei". Além de classificar as iniciativas do PCB na região como "mentiras comunistas", o relatório aponta que as mobilizações de qualquer natureza arquitetadas pelos pecebistas evidenciam a "pobreza de imaginação que caracteriza a agitação comunista". 0 "embuste" movimentado pelo PCB na localidade facilitou o surgimento da "luta pela terra e a campanha de auxílio e assistência aos 'camponeses' de Porecatu". ${ }^{49}$

Londrina teria sido o centro nervoso das operações que subsidiaram tal revolta, pelo fato de a direção pecebista na região ser sediada na cidade. Os veículos de comunicação, mantidos pelo partido, contribuíam na disseminação do "perigo" vermelho. Em Londrina era impresso o jornal "O Momento", classificado pela polícia política como "agitador coletivo", além de serem redigidos panfletos e boletins de "agitação e incitamento". ${ }^{50}$ Periodicamente, conforme levantamento da DOPS Regional, o dr. Newton Camara e Manoel Jacinto Correia espalhavam pelas ruas da cidade panfletos e boletins ${ }^{51}$ alimentando a ideia de que a solução pela ausência das liberdades democráticas e contra o imperialismo estadunidense estaria na "luta pelo progresso e bem estar comum, com a classe operária à frente". ${ }^{52}$

48 FUNDO DOPS/DEAP. Pasta Delegacia de Polícia de Londrina, n 544d, top: 6, p. 148.

49 Ibidem. p. 149.

50 Ibidem. p. 148-149.

51 FUNDO DOPS/DEAP. Pasta Delegacia de Polícia de Londrina, n 544d, top: 61. Relatório reservado. Londrina, 2 de maio de 1950, p. 162.

52 FUNDO DOPS/DEAP. Pasta Delegacia de Polícia de Londrina, n 544d, top: 61. Panfleto “Ao povo de 
Para a DOPS, tais líderes do setentrião paranaense disseminavam os ideais comunistas e pregavam um discurso de ameaça a supremacia do Estado, pois estimulavam os trabalhadores a contestar as condições de exploração a que eram submetidos. A propaganda exigia a união de todas as atividades e ideologias. Sua linguagem simples, imagética e agressiva procurava provocar paixões para atingir diretamente as massas. Contrapondo a divulgação política de "insinuações indiretas" e práticas ameaçadoras executadas pelo sistema policial, a propaganda comunista se fazia mais sedutora aos olhos dos trabalhadores, sendo interpretada, na ótica policial, como um sinônimo de conspiração contra a ordem pública imposta pelo Estado.

Partilhando da autonomia adquirida por meio da Constituição de 1946, atrelada à legitimação da "justiça repressiva" concedida pela Carta Magna do Paraná, o governo Dutra e, em âmbito estadual, a gestão de Moysés Lupion, responderam ao crescimento do PCB com medidas restritivas que culminaram com o expurgo de funcionários públicos pertencentes ao Partido Comunista em 1946 e a cassação de seu registro eleitoral no ano seguinte. A crença de que uma conspiração meticulosamente orquestrada pelo PCB estava a caminho assombrava os setores anticomunistas a ponto de estimulá-los a confeccionar representações do comunismo como uma força maléfica, um braço da União Soviética plantado para propagar a desordem e estabelecer um sistema contínuo de lutas entre classes antagônicas. Tais representações resultaram na origem do "mito da conspiração comunista", temor constante da perda do poder para os "partidários de Moscou", e no "mito fundador" como um sistema de valorização do nacionalismo visando depreciar elementos estrangeiros. Tais construções mitológicas foram significativas para a manutenção de círculos conservadores e conformistas.

\section{CONCLUSÃO}

Fontes não falam por si. Para que o historiador consiga estabelecer um diálogo com a documentação, é pertinente que sejam estabelecidos procedimentos teórico-metodológicos ajustados a seus interesses analíticos. No caso, dois conceitos centrais interpretados na história política são particularmente essenciais: "mito" e "imaginário social".

Como órgão gerenciador de informações arquivadas e complementares, a DOPS e suas "filiais" estaduais garantiram a perpetuação de mitos. No período em questão, é imperioso o mito da conspiração comunista in-

Londrina". p. 163. 
ternacional e a maneira como este se cristalizou no imaginário social. Para a polícia política norte paranaense, o PCB seria o responsável pelas "imperfeições da sociedade", além de sempre estar presente "para explorar, para agitar e para mais fundo cavar na discórdia" e estabelecer, no setentrião paranaense, "um clima de insurreição e subversão da ordem". ${ }^{53} \mathrm{Se}$, para o século XIX, Raul Girardet ${ }^{54}$ destacou a eminência de três tipos de mitos conspiratórios, dada à natureza oculta dessas organizações: o complô judeu, o complô jesuítico e o complô maçônico, pode-se dizer que no século XX figura, entre uma das conspirações, o complô comunista. ${ }^{55}$

Para a polícia política, os comunistas contavam com o apoio de órgãos de imprensa para difundir seu credo entre os "ignorantes". Viam o partido como um instrumento meticulosamente ordenado. Em virtude da presença do PCB em Londrina, afirmavam que diante da situação crítica de movimentos sociais residiam nessa cidade "alguns dos mais operosos dirigentes da agitação comunista do Paraná”, e por causa dessa repercussão doutrinária entre as massas "havia o Partido Comunista situado o comando da ação subversiva". ${ }^{56}$

Nesse caso, o mito da conspiração comunista assume um caráter republicano atrelado a outro mito: o da nacionalidade (ou brasilidade), que se esforçava em integrar o indivíduo à nação. Como um organismo internacional, o Partido Comunista contradizia essa lógica. Aqueles que não se enquadravam no modelo arquitetado pelo regime eram rotulados "indesejáveis" e eram perseguidos, vigiados e eliminados.

O enfoque aqui abordado privilegiou a presença de uma lógica simbólica orientando o papel da DOPS em relação aos comunistas no norte do Paraná. Inclusa entre os conservadores, a polícia política tratava os comunistas como "inimigos da pátria", associando-os a elementos desagregadores, semeadores da desordem e contrários à unidade orgânica do país. Considerados "estrangeiros", os comunistas eram tratados como "o outro", um "câncer" social que se infiltrou no corpo da nação para desestabilizar sua saúde. Portanto, competia aos responsáveis pela segurança extirpar esse mal e defender a pátria. Assim, não havia preocupação com a tolerância, uma vez que a gravidade do perigo justificava qualquer tipo de repressão.

53 FUNDO DOPS/DEAP. Pasta Delegacia de Polícia de Londrina, n 544d, top: 61, p. 148.

54 GIRARDET, op, cit.

55 Ibidem. p. 32.

56 FUNDO DOPS/DEAP. Pasta Delegacia de Polícia de Londrina, n 544d, top: 61, p. 147-148. 
A associação do comunismo a patologias incuráveis estava associada à ideia da prevenção como forma de evitar a medicação. Tal discurso facilitava a formação de frentes anticomunistas, estimulando a denúncia em relação aos suspeitos em nome da união nacional. Os brasileiros deveriam se acoplar, independentemente das diferenças que os separavam, para combater essa doutrina "exótica" que poderia contaminar a população se expandindo para os rincões do país. Para representá-los havia o braço forte da polícia política. Para tanto, na década de 1940, documentos de caráter policial remetiam a imagem da Insurreição de 1935 para rememorar os brasileiros do perigo eminente que representava o comunismo. Consideradas ricas em detalhes, as evidências elaboradas pela polícia política mostram o ponto de vista oficial, com grande capacidade de convencimento. Na maioria das vezes, insistem em demonstrar a eminência de algum "perigo" ou "ameaça" social. Após o Estado Novo, a advertência policial era mais recorrente em relação aos comunistas. Era um momento fértil para o surgimento de mitos políticos, entre os quais figuraram o mito da conspiração comunista e o ideário da brasilidade.

Desse modo, as atividades desenvolvidas pela DOPS no setentrião paranaense indicam, por um lado, que a polícia política, experimentando certo grau de autonomia, obteve sucesso ao elaborar a "lógica" de um "perigo vermelho" ou mito da conspiração comunista, considerando a mobilização dos agentes e da sociedade civil para combater este mal. Por outro lado, o autoritarismo em pleno período considerado democrático, refletido nas práticas da polícia política, levou esta a agir, muitas vezes, de forma abusiva. Atribuir, de forma generalizada e sem uma análise minuciosa de que os pecebistas, camponeses e trabalhadores nutriam a intenção de estabelecerem uma extensão do comunismo soviético no norte do Paraná, acreditando terem eles conspirado secretamente a favor destes objetivos, é partilhar do terreno do mito, vinculado a uma construção de imagens e significados que redirecionam ao temor da perda de espaço e poder político.

Artigo recebido para publicação em: 20/07/2012

Artigo aprovado para publicação em: 16/12/2013 